\title{
Preproenkephalin Knockout Mice Show No Depression-Related Phenotype
}

\author{
Andras Bilkei-Gorzo*,', Kerstin Michel', Florence Noble ${ }^{2}$, Bernard P Roques ${ }^{2}$ and Andreas Zimmer' \\ 'Department of Molecular Psychiatry, University of Bonn, Bonn, Germany; '2 Département de Pharmacologie Chimique \& Génétique, \\ INSERM U640_CNRS UMR 815I, UFR des Sciences Pharmaceutiques et Biologiques, Paris, France
}

\begin{abstract}
Clinical, preclinical, and pharmacological studies have suggested that decreased enkephalin tone is associated with depression-like symptoms and increase in enkephalin signaling could have a therapeutic value in the treatment of depression. In this study we demonstrate that, surprisingly, animals lacking enkephalin (preproenkephalin, Penkl ${ }^{-/-}$) showed no depression-related phenotype in the Porsolt forced swimming or tail suspension tests. Moreover, Penkl ${ }^{-1-}$ mice had a lower frequency of depression-related behavior in stress-induced hypoactivity and ultrasonic vocalization models of depression, similar to animals treated with antidepressant drugs, although this effect was specific to the genetic background. In addition, there was no significant difference in the efficacy of antidepressant reference compounds in wild-type and knockout animals. Nialamide and amitriptyline were even slightly more effective in animals with genetic deletion of Penkl, whereas the minimal effective dose of imipramine and fluoxetine was the same in the two genotypes. The dual peptidase inhibitor RB-IOI was also effective in Penkl ${ }^{-1-}$ as well as in Penkl $I^{-1-} / \mathrm{Pdyn}^{-1-}$ animals, although its efficacy was somewhat reduced compared with wild-type animals. This result was also surprising because the antidepressant effects of RB- $|0|$ were thought to be due to the elevation of enkephalin levels.

Neuropsychopharmacology (2007) 32, 2330-2337; doi: I 0. I038/sj.npp. I 301370; published online 2I March 2007
\end{abstract}

Keywords: enkephalin; knockout; depression; antidepressant drugs; animals model; enkephalinase inhibitor

\section{INTRODUCTION}

Several independent studies suggested a role of enkephalins in depression. In the chronic mild stress model of depression, which has a high face validity, enkephalin levels in the nucleus accumbens were decreased (DziedzickaWasylewska and Papp, 1996). Similarly, a blunted enkephalin release was found after exposing chronic mild stressed animals to a conspecies (Bertrand et al, 1997). These and other studies led to the conclusion that depressive behaviors, especially anhedonia, may be related to the reduced levels or responsiveness of enkephalin neurotransmission in the nucleus accumbens (Zangen et al, 2002). However, in contrast to these findings there was an increased enkephalin immunoreactivity in limbic structures (Primeaux and Holmes, 2000) and ventral striatum, but not in the nucleus accumbens (Holmes, 1999) in the bulbectomy model of depression. It was suggested that this increase, at least partly, contributes to the behavioral changes observed

*Correspondence: Dr A Bilkei-Gorzo, Department of Molecular Psychiatry, University of Bonn, Sigmund-Freud-Strasse 25, 53127 Bonn, Germany, Tel: + 492286885 317, Fax: + 492286885301 ,

E-mail: abilkei@uni-bonn.de

Received 3 October 2006; revised 3 January 2007; accepted 10 January 2007 after bulbectomy since increase of enkephalin level through viral gene transfer in the ventral striatum mimicked some effects of bulbectomy (Primeaux et al, 2003).

Increased enkephalin levels after pharmacological blockade of enkephalin-degrading enzymes resulted in a reduction of depression-related behaviors in animal models (Tejedor-Real et al, 1993, 1995). This effect is probably mediated by an enhanced delta opioid receptor (DOPr) activity, because similar results have been obtained by application of DOPr agonists (Broom et al, 2002) and because DOPr knockout mice showed an increased frequency of depression-like behavior in the forced swimming test (Filliol et al, 2000).

It has been demonstrated that enkephalin levels are increased by the classical antidepressant imipramine (Dziedzicka-Wasylewska and Papp, 1996) through inhibition of enkephalin degradation (de Gandarias et al, 1999). This effect of imipramine may contribute to its therapeutic effects. Decrease of enkephalin signaling through the blockade of DOPr with naltrindole antagonized the antidepressant effect of agmatine in the forced swimming test (Zomkowski et al, 2005). Moreover, the antidepressant effect of imipramine or iprindole was potentiated using inhibitors of enkephalin degrading peptidases (de Felipe et al, 1989). There are two enzymes participating in the degradation of enkephalins, the neutral endopeptidase or 
enkephalinase (EC 2.4.24.11) and aminopeptidase N (EC 3.4.11.2). The analgesic and antidepressant properties of these drugs are thought to base on their ability to increase the enkephalin levels (Nieto et al, 2005). However, it should be noted that these enzymes also act on a number of other peptides such as substance $\mathrm{P}, \mathrm{CGRP}$, and angiotensin.

The aim of the present study was to elucidate the role enkephalin plays in depression-like behavior and in the mechanism of action of classical antidepressants and 'enkephalinase inhibitors' using preproenkephalin (Penk1) knockout animals. Since we have previously shown that the genetic background can interfere with the manifestation of the Penk1 mutant phenotype, we have included Penk $1^{-1-}$ mice on C57BL/6J and DBA/2J genetic backgrounds. These two strains represent different branches in the mouse family tree and differ in many behavioral traits (Witmer et al, 2003).

\section{MATERIALS AND METHODS}

\section{Animals}

The generation of Penk1 mutant mice on C57BL/6J and DBA/2J congenic backgrounds has been described (Konig et al, 1996; Bilkei-Gorzo et al, 2004). Mice lacking Penk $1^{-1-}$ and preprodynorphin $\left(\mathrm{Pdyn}^{-1-}\right)$ were generated by crossing homozygous $\mathrm{Pdyn}^{-1-}$ animals on a congenic C57BL/6J genetic background (Zimmer et al, 2001) with homozygous C57BL/6J-Penk ${ }^{-I-}$ mice. The resulting double heterozygous Penk $1^{+/-} /$Pdyn $^{+/-}$animals were intercrossed to obtain the homozygous double Penk $1^{-/-} / \mathrm{Pdyn}^{-/-}$mutants and wild-type Penk $1^{+/+} / \mathrm{Pdyn}^{-/-}$controls. Male Penk $1^{-/-}$and Penk $1^{+/+}$mice (3-5 months old) were kept in a reversed light-dark cycle at least 2 weeks before testing and housed in groups of 3-5. Each animal was used only once and was naive to the model. Experiments were carried out in the active (dark) phase between 10 and $16 \mathrm{~h}$. The experimenter was blind to knockout genotype. Animal procedures followed the guidelines of the German Animal Protection Law.

\section{Forced Swimming Test}

Animals were placed in a Plexiglas cylinder $(10 \mathrm{~cm}$ internal diameter, $50 \mathrm{~cm}$ high) filled with $22-23^{\circ} \mathrm{C}$ water $(10 \mathrm{~cm}$ height). Duration of the experiment was $6 \mathrm{~min}$, the behavior of the animals was evaluated between the 2nd and 6th minute for $4 \mathrm{~min}$. The immobility time was measured using a stopwatch. A mouse was judged to be immobile when it remained floating in the water, making only those movements necessary to keep its head above the water (Porsolt et al, 1977; Porsolt, 2000). Means and standard errors were calculated for each group. Wild-type and knockout animals with the same genetic background were compared using the Student's $t$-test.

\section{Tail Suspension Test}

Mice were suspended by their tails from a metal rod, which was fixed $50 \mathrm{~cm}$ above the surface of a table covered with soft cloth in a sound-isolated room. The tip of the tail was fixed using adhesive Scotch tape; the duration of the test was 6 min. The immobility time was determined with a stopwatch (Steru et al, 1985). This behavioral model was carried out only on animals on a DBA/2J genetic background, since majority of C57BL/6J mice climb up their tail in the tail suspension test situation (Mayorga and Lucki, 2001). Mean and standard error values were calculated, and groups were compared using the Student's $t$-test.

\section{Stress-Induced Hypomotility}

The animals were placed into an open-field arena with a grid floor (Conducta, Experimetria Ltd, Hungary) and their motor activity was registered for $5 \mathrm{~min}$. Just after this period, mice received 10 inescapable foot shocks $(2 \mathrm{~s}$, $500 \mathrm{~mA}$ ) with $30 \mathrm{~s}$ intervals. About $24 \mathrm{~h}$ later we placed the animals back to the same arena and registered their motor activity for $5 \mathrm{~min}$. Hypomotility was calculated as difference in distance traveled before and after the stress exposure. Data were analyzed using two-way ANOVA (within factor: time; between factors: genotype) followed by LSD test separately in both genetic backgrounds.

\section{Ultrasonic Vocalization}

About 5-7-day-old pups were removed from the dam, placed individually into a glass jar, and put into a soundisolated box kept at room temperature $\left(23 \pm 1^{\circ} \mathrm{C}\right)$. The duration and number of ultrasonic calls was registered using the Ultravox system (Noldus, The Netherlands) for 5 min. Groups were compared using Mann-Whitney test.

\section{Antidepressant Treatment}

Animals were treated with vehicle or drug either intraperitoneally $30 \mathrm{~min}$ before, or intravenously $5 \mathrm{~min}$ before the test. A separate control (vehicle-treated) group was used for each drug in each genotype. The MAO inhibitor nialamide was suspended in saline with the help of a drop of Tween 20 and tested in the dose range of $25-150 \mathrm{mg} / \mathrm{kg}$. The tricyclic uptake inhibitors amitriptyline and imipramine were dissolved in saline and were used in a dose range of $1-20 \mathrm{mg} / \mathrm{kg}$. The specific serotonin reuptake inhibitor fluoxetine was dissolved in saline and tested in the doses of 10 and $20 \mathrm{mg} / \mathrm{kg}$. The forced swimming test was carried out as described above. RB-101 was dissolved in ethanol (10\%), Cremofor EL (10\%) and distilled water (80\%). Animals were injected through the tail vein with the help of a restrainer with the vehicle or the drug intravenously and tested $10 \mathrm{~min}$ after the treatment as described above. The efficacy of drugs was evaluated using one-way ANOVA, the effect of individual doses using Dunnett's test.

\section{Effect of the Delta Receptor Antagonist Naltrindole on the Antidepressant Activity of RB-101}

Mice were first injected s.c. with $3 \mathrm{mg} / \mathrm{kg}$ naltrindole or vehicle. About 30 min later, the animals were treated with RB101 or vehicle and tested in the forced swimming paradigm as described above. Data were analyzed using one-way ANOVA followed by Bonferroni test. 

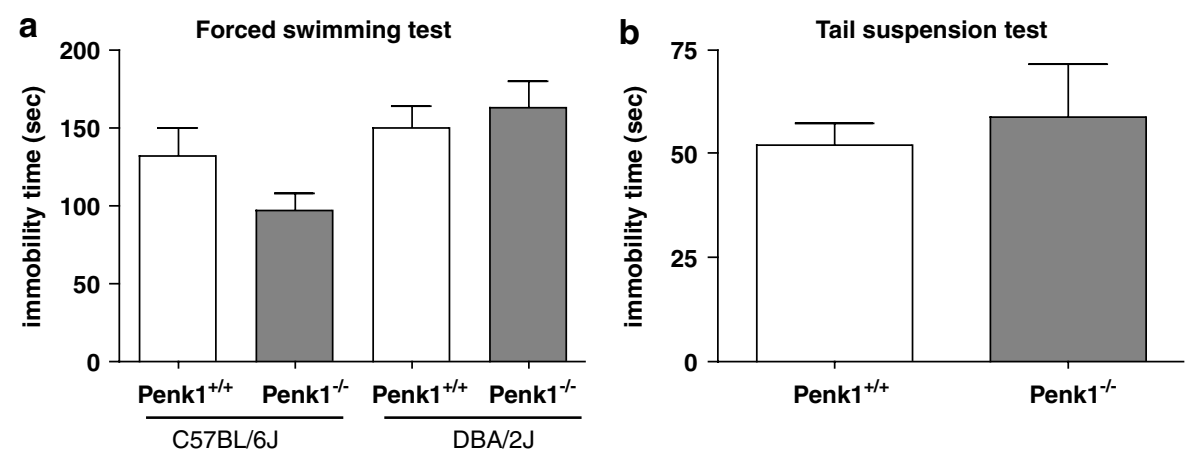

Figure I (a) Time spent with immobility did not differ in wild-type and Penk $\left.\right|^{-1-}$ mice on a C57BL/6J $\left(t_{18}=1.63\right.$, not significant $)$ or DBA/2 $\left(t_{18}=0.56\right.$, not significant) genetic background. (b) Deletion of Penk $\left.\right|^{-1-}$ did not influence the behavior of animals in the tail suspension test $\left(t_{18}=0.48\right.$, not significant). Columns represent column means ( + SEM) $(n=10)$.
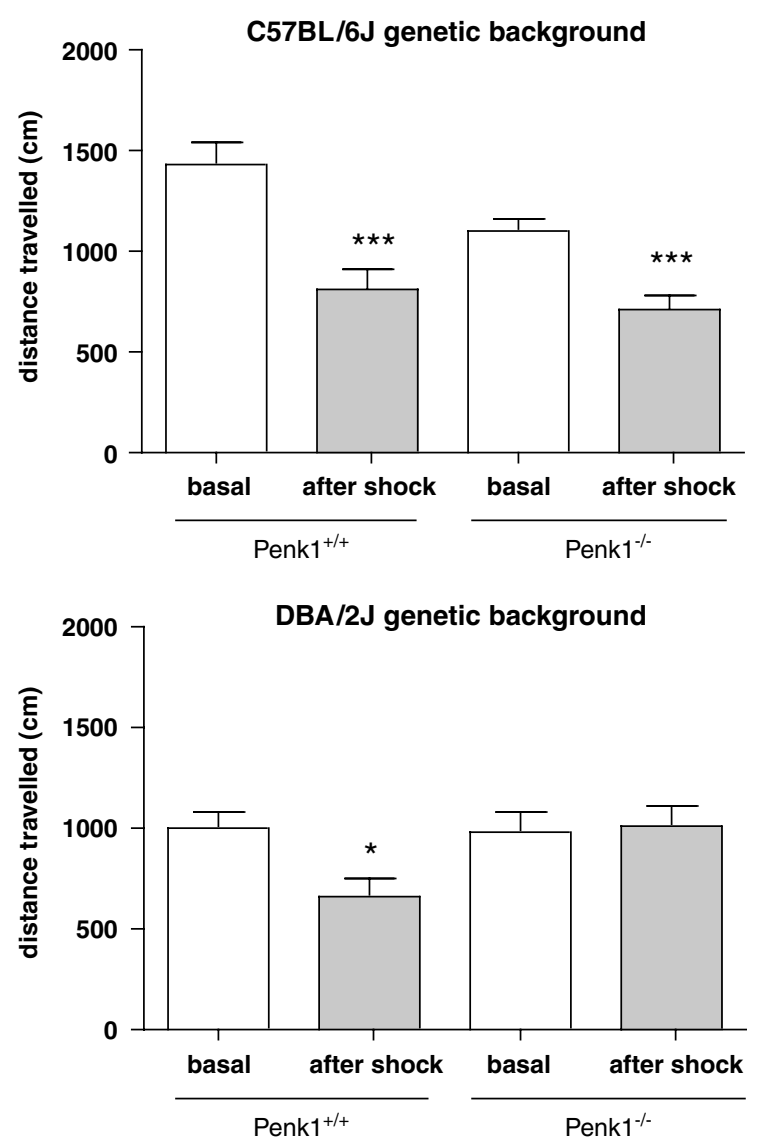

Figure 2 Horizontal activity of animals was measured in an open field just before and $24 \mathrm{~h}$ after receiving 10 electric foot shocks. Hypomotility was not present in PenkI ${ }^{-/-}$mice on a DBA/2J genetic background, whereas knockout mice on a C57BL/6J background had the same stress reactivity as wild-type mice. Columns represent group means (+ SEM) $(n=10) . *{ }^{*} p<0.01$; ***** $p<0.00$ I two-way ANOVA followed by LSD $t$-test.

\section{RESULTS}

\section{Behavioral Despair Models}

We evaluated two behavioral despair models: Porsolt's forced swim and the tail suspension tests. In these tests, antidepressant drugs reduce the time, animals remain
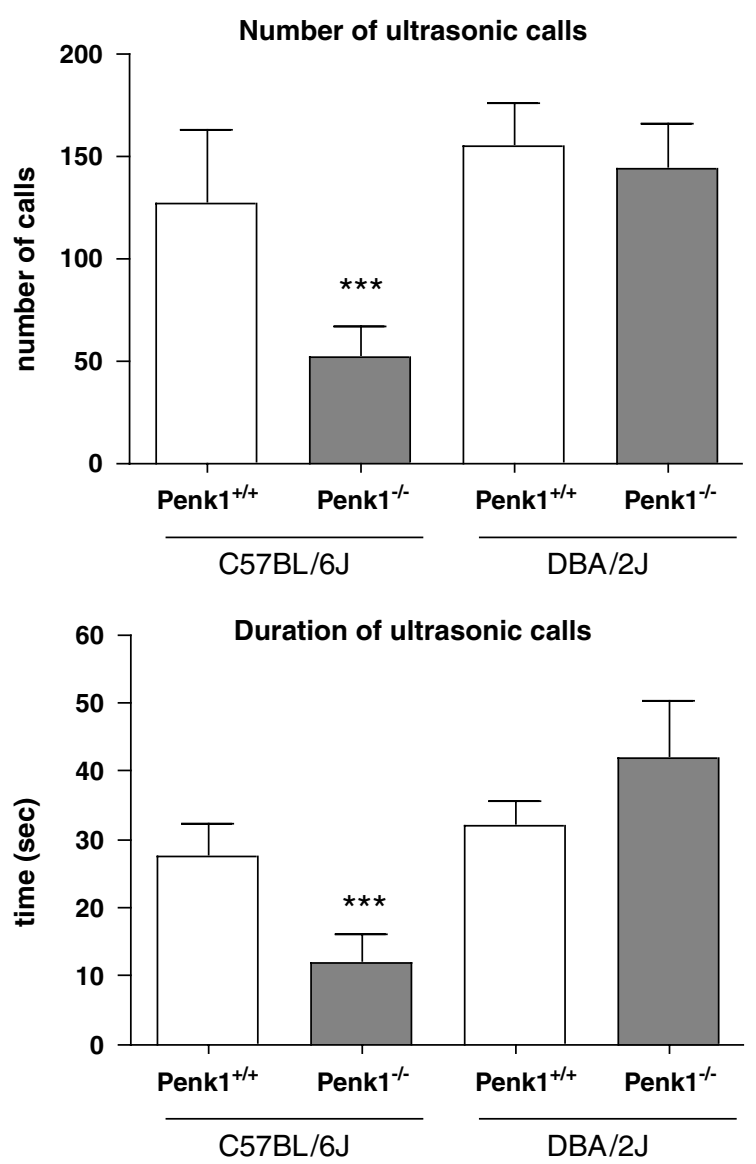

Figure 3 The number and duration of ultrasonic calls in mouse pups was significantly lower in Penk $I^{-1-}$ mice compared to wild-type animals on a C57BL/6) $(U=194.5 ; p<0.00$ I for the number and $U=\mid 45,0 ; p<0.001$ for the duration) but not on a DBA/2J genetic background. Each column represents the mean value ( + SEM) of $23-28$ animals. $* * * * 0<0.001$ unpaired Student's t-test.

motionless (behavioral despair), and conversely, increase the time in which animals struggle trying to escape. First we analyzed mice on a DBA/2J genetic background. Deletion of Penk1 gene did not change the behavior of animals in the forced swimming test (Figure 1a). Because the genetic background may influence the manifestation of the phenotype (Bilkei-Gorzo et al, 2004), we repeated the 
experiment with wild-type and knockout animals on a C57BL/6J background. Animals with genetic deletion of the Penk1 gene showed again a same depression-related behavior as wild-type mice (Figure 1a). DBA/2J mice of both genotypes also behaved similar in the tail suspension test (Figure 1b). We did not use mice from the C57BL/6J background in this assay, because C57BL/6J mice are known to climb up on their own tails (Mayorga and Lucki, 2001).

\section{Stress-Induced Hypomotility}

This paradigm evaluates the activity of animals in an open field system, in which they were exposed previously to inescapable foot shocks. The motility of the animals was significantly lower $24 \mathrm{~h}$ after the electric foot shock both in wild-type and knockout mice on the C57BL/6J genetic background shown by the lack of interaction between stress and genotype $\left(\mathrm{F}_{1,18}=0.59 ; p>0.05\right)$. The amplitude of reduction was $-43.2 \%$ in Penk $1^{+/+}\left(t_{9}=6.14 ; p<0.001\right)$ and $-35.5 \%$ in Penk1 ${ }^{-1-}\left(t_{9}=8.34 ; p<0.001\right)$ animals. However, Penk $1^{+/+}$and Penk $1^{-1-}$ mice on a DBA/2J genetic background showed significantly different reactivity to foot shock stress $\left(\mathrm{F}_{1,18}=7.10 ; p<0.05\right)$. LSD post hoc test revealed that stress-induced hypomotility was present in Penk $1^{+/+}(-30.3 \% ; p<0.05)$, but not on Penk $1^{-7-}$ animals $(+3.00 \% ; p>0.05)$ (Figure 2).

\section{Ultrasonic Vocalization}

Mouse pups placed on a hard and cold surface isolated from the dam emitted a series of ultrasonic calls. The number and the duration of the calls were significantly lower in Penk $1^{-l-}$ animals on a C57BL/6J genetic background (Figure 3). In contrast, knockout animals on a DBA/2J
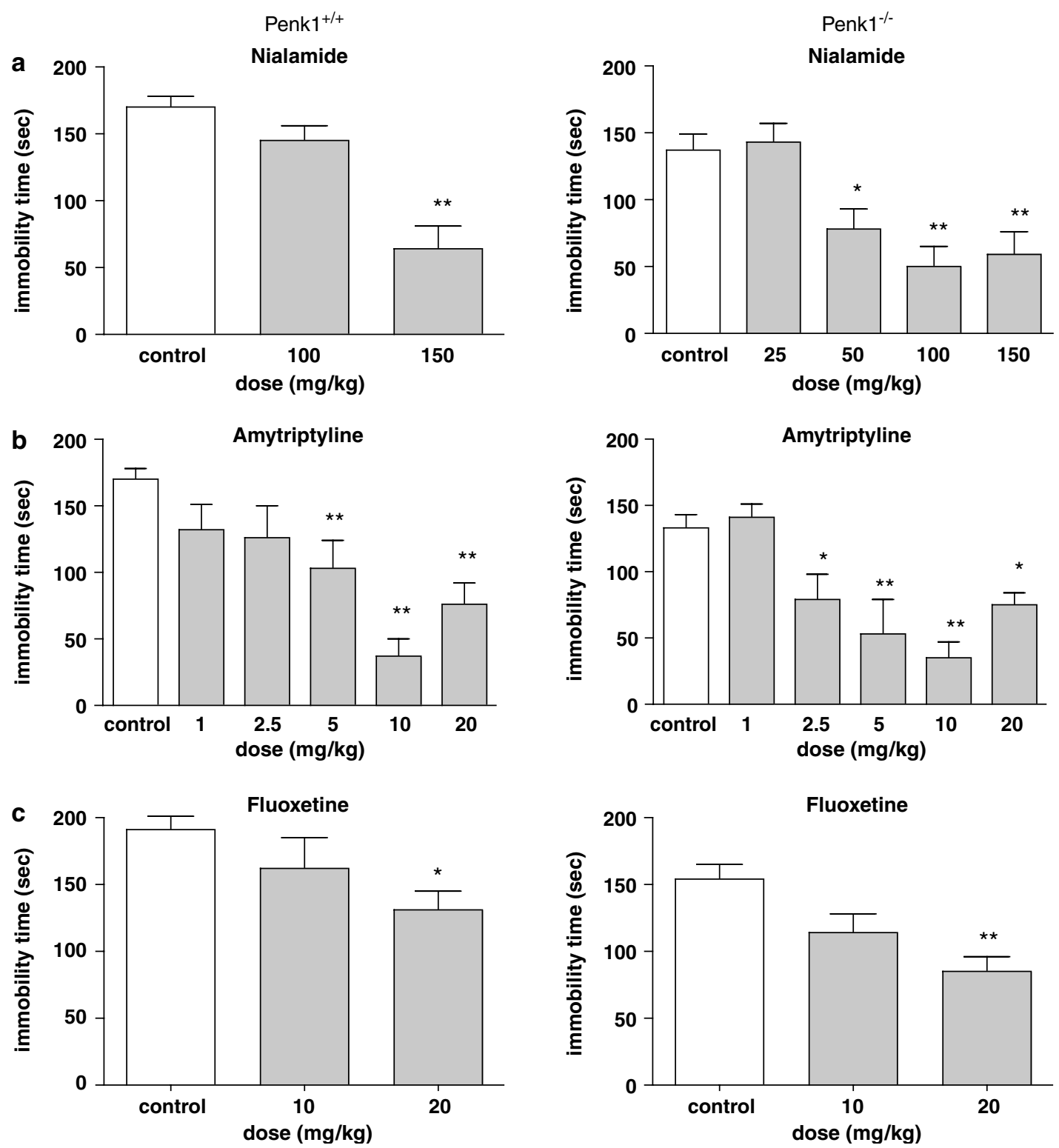

Figure 4 Activity of antidepressant reference compounds in forced swimming test in wild-type and Penk $\left.\right|^{-1-}$ mice. Each column represents the mean value ( + SEM) of $8-10$ animals. $* p<0.05$; $* * p<0.01$; one-way ANOVA followed by Dunnett's test. 
genetic background did not show alteration in the ultrasonic vocalization (Figure 3 ).

\section{Effect of Antidepressants in the Forced Swimming Test}

Reference drugs and RB101 were first tested in wild-type and Penk $1^{-l-}$ mice on a DBA/2J genetic background. The MAO inhibitor nialamide significantly reduced the time spent with immobility both in wild-type and in knockout mice, but its efficacy was higher in the later group since the minimum effective dose (MED) value was $150 \mathrm{mg}$ in wildtype and $50 \mathrm{mg} / \mathrm{kg}$ in the Penk $1^{-/-}$animals (Figure $4 \mathrm{a}$ ). The tricyclic uptake inhibitor, amitriptyline, was slightly more effective in Penk $1^{-I-}$ mice $(2.5 \mathrm{mg} / \mathrm{kg})$ compared with Penk $1^{+1+}$ animals $(5 \mathrm{mg} / \mathrm{kg}$, Figure $4 \mathrm{~b}$ ), whereas fluoxetine was effective in the highest dose tested $(20 \mathrm{mg} / \mathrm{kg})$ in mice of both genotypes (Figure 4c). The antidepressant effects of imipramine and RB-101 were studied in wild-type and Penk1 knockout mice on both C57BL/6J and DBA/2J genetic backgrounds. Imipramine and RB-101 had a similar effect in wild-type mice and animals with genetic deletion of Penk1 gene regardless of the genetic background (Figures 5 and 6). Because enkephalins may also be produced from Pdyn, one cannot exclude the possibility that enkephalins are still present in the absence of a functional enkephalin gene, even though we failed to detect any residual enkephalins in striatal extracts of Penk $1^{-1-}$ mice (Konig et al, 1996). Therefore we tested the activity of RB-101 on Penk1 $^{-1-} / \mathrm{Pdyn}^{-1-}$ double knockout animals. RB-101 remained active also in the absence of Penk1 and Pdyn (Figure 6).

\section{Effect of the Delta Receptor Antagonist Naltrindole on the Antidepressant Activity of RB-101}

Naltrindole had no effect on the immobility time of wildtype DBA/2J mice, but significantly reduced the antidepressant effect of RB-101 (Figure 7). Naltrindole remained inactive when administered alone in the Penk $1^{-1-}$ mice, but it partially antagonized the effect of RB-101. The immobility time of mice treated with naltrindole and RB-101 did not differ from the immobility times measured in control or RB101-treated animals (Figure 7).

\section{DISCUSSION}

Previous studies suggested a correlation between enkephalin levels and depression-related behavior, as alterations in brain enkephalin levels were detected in the chronic mild stress (Dziedzicka-Wasylewska and Papp, 1996) and bulbectomy (Primeaux and Holmes, 2000) models of depression. Moreover, activation of the enkephalin system either with DOPr agonists or agents blocking the degradation of enkephalin yielded a decrease in depressive symptoms (Tejedor-Real et al, 1998). The results from these pharmacological studies were confirmed by the analysis of mice with genetic deletion of DOPr. These animals displayed a significant increase in immobility time, which was interpreted as a sign of increased proneness to depressionrelated behavior (Filliol et al, 2000). On the basis of this evidence, we have hypothesized that enkephalin deficient mice would also display more depression-related behaviors. However, the reactivity of Penk $1^{-1-}$ animals either did not
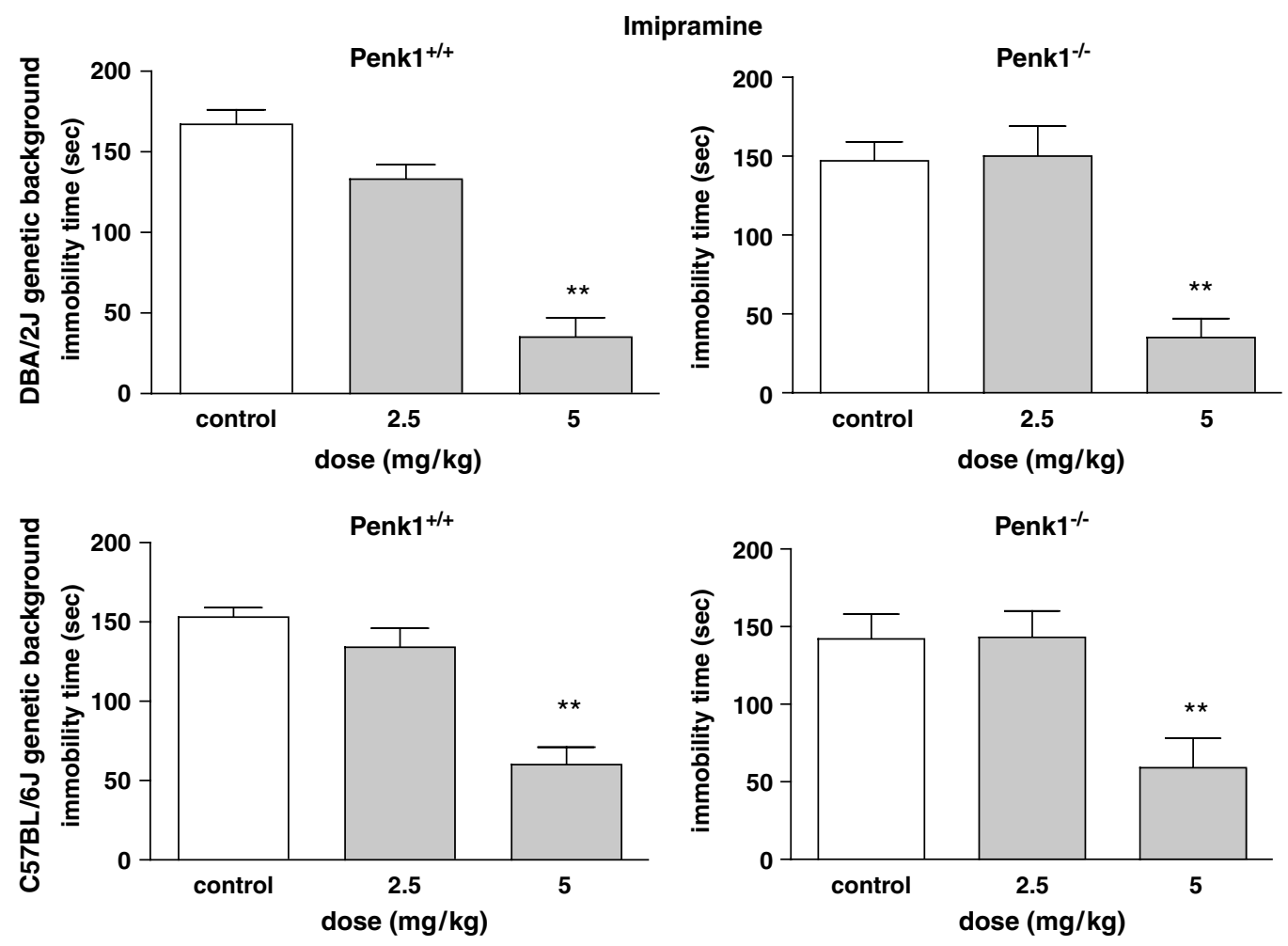

Figure 5 Activity of imipramine in forced swimming test in wild-type Penk ${ }^{-1-}$ mice on C57BL/6J and DBA/2J genetic backgrounds. Each column represents the mean value ( + SEM) of 7-10 animals. ${ }^{*} * 0.01$ one-way ANOVA followed by Dunnett's test. 


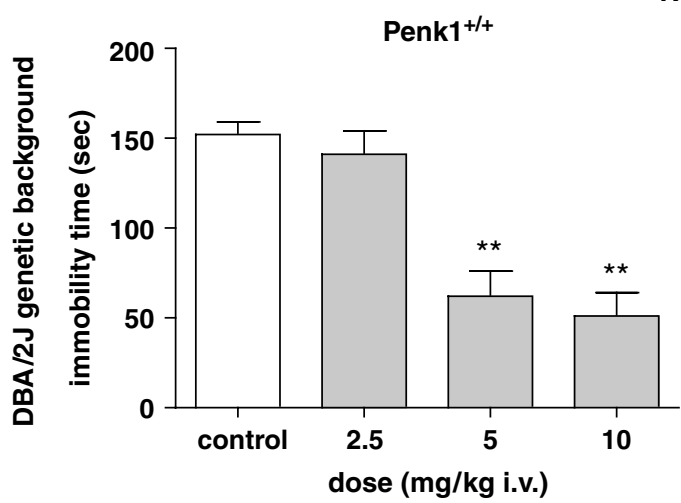

RB-101
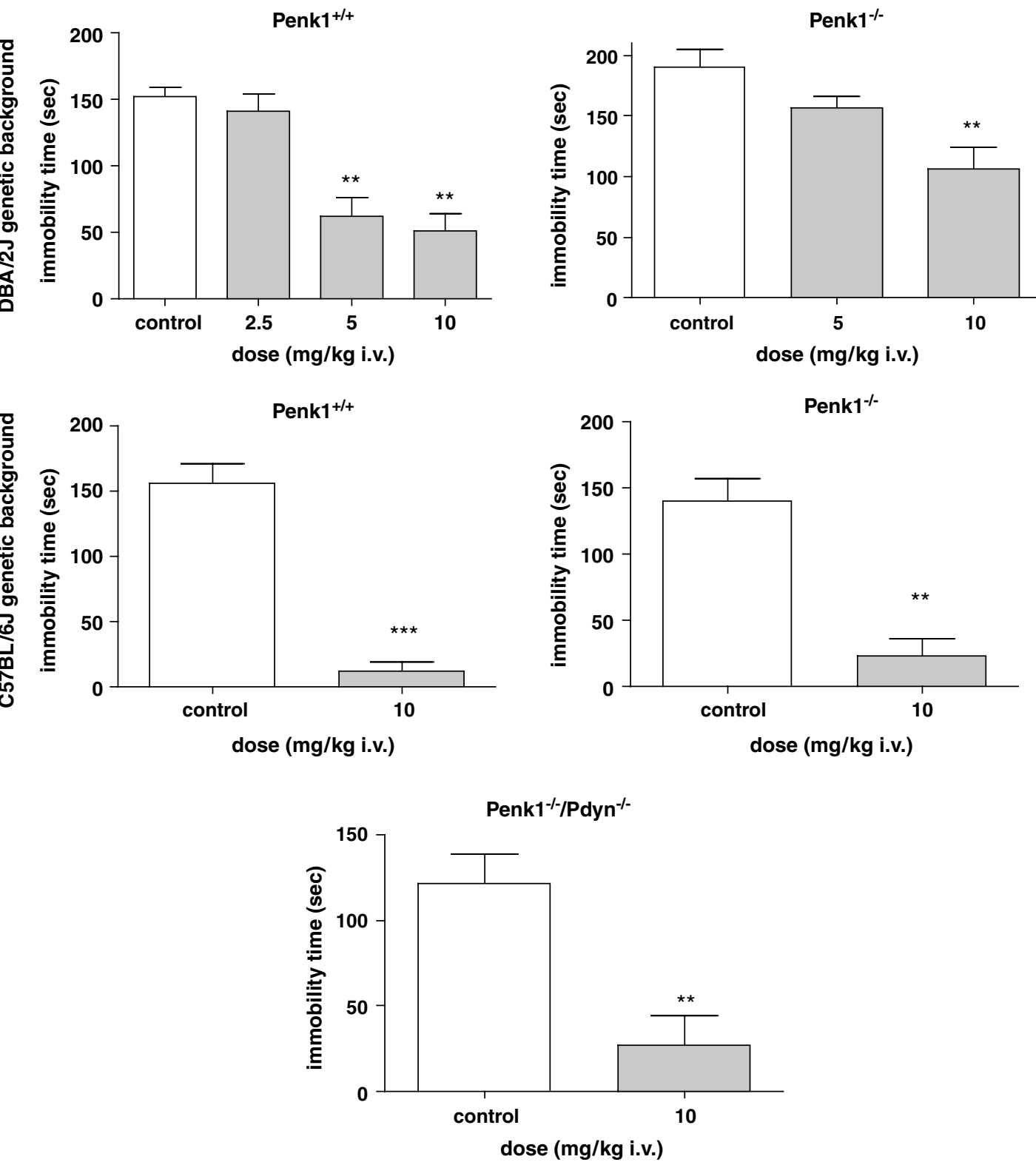

Figure 6 Activity of dual inhibitor RB- IOI in forced swimming test in wild-type, Penk $\left.\right|^{-1-}$, and Penk $\left.\right|^{-1-} /$ Pdyn $^{-1-}$ mice. Each column represents the mean value ( + SEM) of $8-10$ animals. $* * * 0.01$; *** $p<0.00$ I one-way ANOVA followed by Dunnett's test.

differ from wild-type animals in two different models of depression or showed even a reduction in depressionrelated behavior dependent on the genetic background. Although C57BL/6J and DBA/2 mice are known to differ substantially in several animal models of depression (Ripoll et al, 2003; Ducottet and Belzung, 2005), the genetic background did not influence the depression-related phenotype, unlike to what we have observed previously with anxiety or pain phenotypes in Penk $1^{-1-}$ mice (BilkeiGorzo et al, 2004). Thus, behavioral analysis of Penk1 knockout animals does not support the hypothesis that a decreased enkephalin signaling contributes to an increase in depression-related behaviors.

One reason of the differences in the depression-related phenotypes between the DOPr (Filliol et al, 2000) and Penk1 knockout animals could be a compensatory change in the absence of enkephalins. Indeed, we have previously shown that the lack of enkephalin leads to an upregulation of opioid receptors in limbic areas (Brady et al, 1999; Clarke et al, 2003). It also seems possible that ambient stress levels may have influenced the different outcomes of these studies. The endogenous opioid system has a relatively low tonicity, but becomes activated upon stress exposure. Chronic mild stress can induce a depression-like state in rodents (Willner, 1997) and affect opioid signaling through the modulation of enkephalin and opioid receptor levels (Drolet et al, 2001).

Several clinical studies that addressed the relationship between depression and the enkephalin system also failed to provide a clear-cut picture. Shortly after the endogenous 

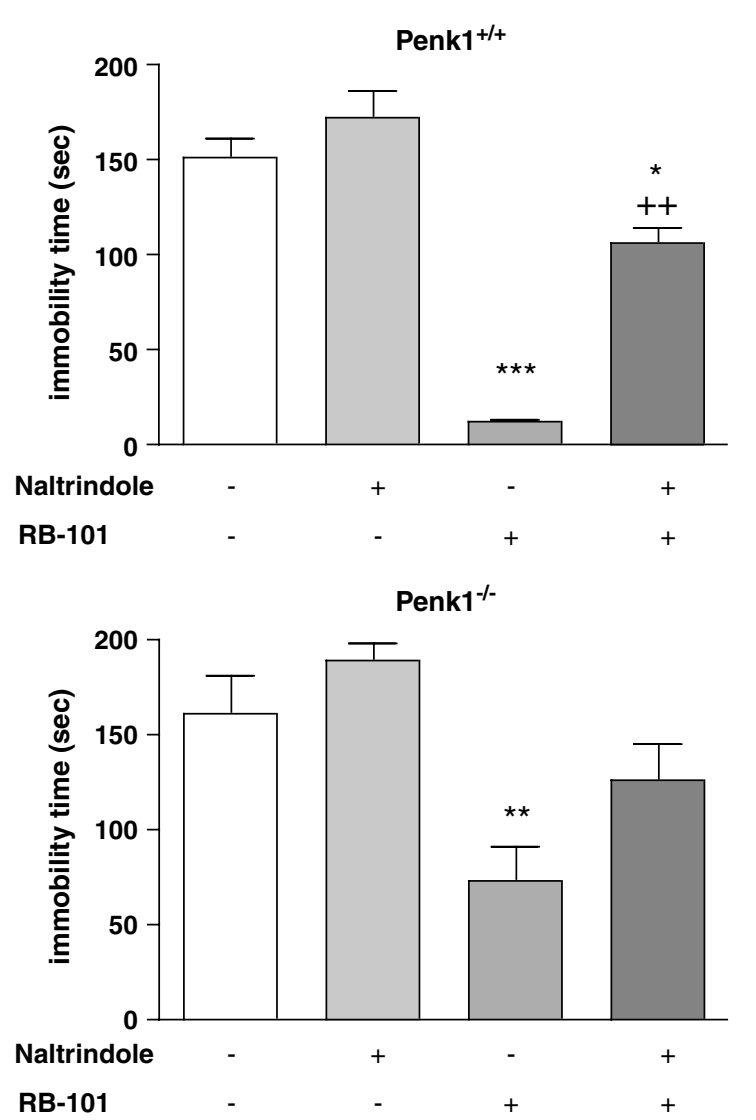

Figure 7 Effect of the DOPr blocker naltrindole on the antidepressant effect of RB-IOI in wild-type and Penk $\left.\right|^{-1-}$ mice. Each column represents the mean value (+SEM) of 8-10 animals. * $p<0.05$; ** $p<0.01$; **** $p<0.001$ vs vehicle-treated group; $++p<0.01$ vs RB-I0I-treated group using one-way ANOVA followed by Bonferroni's test.

opioid system was discovered it was even suggested that depression is an enkephalin deficiency syndrome (Ehrenpreis, 1982). This early hypothesis was not supported by a later clinical study when depressive patients were treated with an enkephalin analog. An alleviation of the symptoms was only observed after the first treatment (Jungkunz et al, 1983). Genetic linkage analysis also did not provide a comprehensive result: one early study excluded the association between Penk1 (Curtis et al, 1993) or neutral endopeptidase (Comings et al, 2000) and depression, but a more recent study found an association between proenkephalin gene and depression (Ogden et al, 2004).

It has been proposed that endogenous opioids, particularly enkephalins, contribute to the antidepressant effect of reference compounds, because their efficacy was antagonized by the non-specific opioid receptor antagonist naloxone (Tejedor-Real et al, 1995) or the DOPr-specific antagonist naltrindole (Zomkowski et al, 2005). Interestingly, the tricyclic catecholamine uptake inhibitor imipramine increased brain enkephalin level by antagonizing the activity of the neutral endopeptidase (de Gandarias et al, 1999). Although this effect was suggested to contribute to the antidepressant activity of the drug, our results do not support this hypothesis. In fact, none of four reference compounds evaluated in this study (nialamide, imipramine, and amitiptyline fluoxetine) showed a reduced efficacy in animals lacking enkephalin. On the contrary, the MED of nialamide and amitriptyline was even lower in the knockout mice. Thus these antidepressants maintained their antidepressant activity in animals with genetic deletion of enkephalin. However, our findings do not exclude the possibility of beneficial effects of increased enkephalin levels in the treatment of depression.

The most surprising result of our experiments was the residual efficacy of the enkephalinase inhibitor RB 101 in animals without enkephalin. The analgesic and antidepressant effect of RB 101 was thought to be based entirely on the elevation of enkephalin levels (Nieto et al, 2005). Nevertheless, RB 101 significantly decreased the time spent with immobility in the forced swimming test, albeit with a reduced efficacy when compared with wild-type animals. The lack of influence of deletion of Penk1 on the antidepressant effect of imipramine and RB-101 was the most surprising, hence we tested these drugs on mice on a C57BL/6J genetic background. Lack of Penk1 gene did not influence the antidepressant effect of the drugs on mice from the C57BL/6J strain, therefore we can exclude that a background gene effect hides the existence of the interaction.

Because it has been reported that enkephalins can also be produced from dynorphin precursors (Brownstein, 1980), we considered the possibility that enkephalin is still present in the absence of Pdyn, and perhaps elevated by the RB101 treatment, although we failed previously to detect any enkephalins in striatal extracts from Penk1 mice using highly sensitive radioimmunoassays (Konig et al, 1996). However, RB-101 still had an antidepressant effect in Penk1 $1^{-l-} / \mathrm{Pdyn}^{+/+}$double knockout animals, which conclusively demonstrates that this drug effect cannot be exclusively dependent on the elevation of enkephalin levels. Furthermore, pharmacological blockade of the DOPrs with naltrindole reduced the effect of RB-101 significantly, but not completely. Together these data suggest that RB-101 either also acts on another substrate, or protects another neuropeptide with antidepressant activity from degradation by the neutral endopeptidase and/or aminopeptidase $\mathrm{N}$. This neuropeptide may even compensate for the lack of enkephalins in Penk $1^{-1-}$ animals and contribute to the absence of a depression-related phenotype in Penk $1^{-1-}$ mice. The identification of this peptide could have a significant impact in depression research.

\section{ACKNOWLEDGEMENTS}

This work was supported by a grant from the German Ministry for Research and Education (NGFN2). The authors declare that they have no competing financial interest.

\section{REFERENCES}

Bertrand E, Smadja C, Mauborgne A, Roques BP, Dauge V (1997). Social interaction increases the extracellular levels of [Met]enkephalin in the nucleus accumbens of control but not of chronic mild stressed rats. Neuroscience 80: 17-20.

Bilkei-Gorzo A, Racz I, Michel K, Zimmer A, Klingmuller D, Zimmer A (2004). Behavioral phenotype of pre-proenkephalin- 
deficient mice on diverse congenic backgrounds. Psychopharmacology (Berlin) 176: 343-352.

Brady LS, Herkenham M, Rothman RB, Partilla JS, Konig M, Zimmer AM et al (1999). Region-specific up-regulation of opioid receptor binding in enkephalin knockout mice. Brain Res $\mathrm{Mol}$ Brain Res 68: 193-197.

Broom DC, Jutkiewicz EM, Folk JE, Traynor JR, Rice KC, Woods JH (2002). Nonpeptidic delta-opioid receptor agonists reduce immobility in the forced swim assay in rats. Neuropsychopharmacology 26: 744-755.

Brownstein MJ (1980). Opioid peptides: search for the precursors. Nature 287: 678-679.

Clarke S, Zimmer A, Zimmer AM, Hill RG, Kitchen I (2003). Region selective up-regulation of micro-, delta- and kappaopioid receptors but not opioid receptor-like 1 receptors in the brains of enkephalin and dynorphin knockout mice. Neuroscience 122: 479-489.

Comings DE, Dietz G, Gade-Andavolu R, Blake H, Muhleman D, Huss $M$ et al (2000). Association of the neutral endopeptidase (MME) gene with anxiety. Psychiatr Genet 10: 91-94.

Curtis D, Sherrington R, Brett P, Holmes DS, Kalsi G, Brynjolfsson $\mathrm{J}$ et al. (1993). Genetic linkage analysis of manic depression in Iceland. $J$ R Soc Med 86: 506-510.

de Felipe MC, Jimenez I, Castro A, Fuentes JA (1989). Antidepressant action of imipramine and iprindole in mice is enhanced by inhibitors of enkephalin-degrading peptidases. Eur J Pharmacol 159: 175-180.

de Gandarias JM, Irazusta J, Varona A, Gil J, Fernandez D, Casis L (1999). Effect of imipramine on enkephalin-degrading peptidases. Eur Neuropsychopharmacol 9: 493-499.

Drolet G, Dumont EC, Gosselin I, Kinkead R, Laforest S, Trottier JF (2001). Role of endogenous opioid system in the regulation of the stress response. Prog Neuropsychopharmacol Biol Psychiatry 25: 729-741.

Ducottet C, Belzung C (2005). Correlations between behaviours in the elevated plus-maze and sensitivity to unpredictable subchronic mild stress: evidence from inbred strains of mice. Behav Brain Res 156: 153-162.

Dziedzicka-Wasylewska M, Papp M (1996). Effect of chronic mild stress and prolonged treatment with imipramine on the levels of endogenous Met-enkephalin in the rat dopaminergic mesolimbic system. Pol J Pharmacol 48: 53-56.

Ehrenpreis S (1982). D-phenylalanine and other enkephalinase inhibitors as pharmacological agents: implications for some important therapeutic application. Acupunct Electrother Res 7: 157-172.

Filliol D, Ghozland S, Chluba J, Martin M, Matthes HW, Simonin F et al (2000). Mice deficient for delta- and mu-opioid receptors exhibit opposing alterations of emotional responses. Nat Genet 25: $195-200$.

Holmes PV (1999). Olfactory bulbectomy increases preproenkephalin mRNA levels in the ventral striatum in rats. Neuropeptides 33: 206-211.

Jungkunz G, Nedopil N, Ruther E (1983). Acute effects of the synthetic analogue of methionine enkephalin FK 33-824 on depressive symptoms. Pharmacopsychiatria 16: 90-92.

Konig M, Zimmer AM, Steiner H, Holmes PV, Crawley JN, Brownstein MJ et al (1996). Pain responses, anxiety and aggression in mice deficient in pre-proenkephalin. Nature 383: $535-538$.
Mayorga AJ, Lucki I (2001). Limitations on the use of the C57BL/6 mouse in the tail suspension test. Psychopharmacology (Berlin) 155: $110-112$.

Nieto MM, Guen SL, Kieffer BL, Roques BP, Noble F (2005). Physiological control of emotion-related behaviors by endogenous enkephalins involves essentially the delta opioid receptors. Neuroscience 135: 305-313.

Ogden CA, Rich ME, Schork NJ, Paulus MP, Geyer MA, Lohr JB et al (2004). Candidate genes, pathways and mechanisms for bipolar (manic-depressive) and related disorders: an expanded convergent functional genomics approach. Mol Psychiatry 9: 1007-1029.

Porsolt RD (2000). Animal models of depression: utility for transgenic research. Rev Neurosci 11: 53-58.

Porsolt RD, Bertin A, Jalfre M (1977). Behavioral despair in mice: a primary screening test for antidepressants. Arch Int Pharmacodyn Ther 229: 327-336.

Primeaux SD, Holmes PV (2000). Olfactory bulbectomy increases met-enkephalin- and neuropeptide-Y-like immunoreactivity in rat limbic structures. Pharmacol Biochem Behav 67: 331-337.

Primeaux SD, Wilson MA, Wilson SP, Guth AN, Lelutiu NB, Holmes PV (2003). Herpes virus-mediated preproenkephalin gene transfer in the ventral striatum mimics behavioral changes produced by olfactory bulbectomy in rats. Brain Res 988: 43-55.

Ripoll N, David DJ, Dailly E, Hascoet M, Bourin M (2003). Antidepressant-like effects in various mice strains in the tail suspension test. Behav Brain Res 143: 193-200.

Steru L, Chermat R, Thierry B, Simon P (1985). The tail suspension test: a new method for screening antidepressants in mice. Psychopharmacology 85: 367-370.

Tejedor-Real P, Mico JA, Maldonado R, Roques BP, Gibert-Rahola $J$ (1993). Effect of mixed (RB 38A) and selective (RB 38B) inhibitors of enkephalin degrading enzymes on a model of depression in the rat. Biol Psychiatry 34: 100-107.

Tejedor-Real P, Mico JA, Maldonado R, Roques BP, Gibert-Rahola $J$ (1995). Implication of endogenous opioid system in the learned helplessness model of depression. Pharmacol Biochem Behav 52: 145-152.

Tejedor-Real P, Mico JA, Smadja C, Maldonado R, Roques BP, Gilbert-Rahola J (1998). Involvement of delta-opioid receptors in the effects induced by endogenous enkephalins on learned helplessness model. Eur J Pharmacol 354: 1-7.

Willner P (1997). Validity, reliability and utility of the chronic mild stress model of depression: a 10-year review and evaluation. Psychopharmacology (Berlin) 134: 319-329.

Witmer PD, Doheny KF, Adams MK, Boehm CD, Dizon JS, Goldstein JL et al (2003). The development of a highly informative mouse Simple Sequence Length Polymorphism (SSLP) marker set and construction of a mouse family tree using parsimony analysis. Genome Res 13: 485-491.

Zangen A, Nakash R, Roth-Deri I, Overstreet DH, Yadid G (2002). Impaired release of beta-endorphin in response to serotonin in a rat model of depression. Neuroscience 110: 389-393.

Zimmer A, Valjent E, Konig M, Zimmer AM, Robledo P, Hahn H et al (2001). Absence of delta -9-tetrahydrocannabinol dysphoric effects in dynorphin-deficient mice. J Neurosci 21: 9499-9505.

Zomkowski AD, Santos AR, Rodrigues AL (2005). Evidence for the involvement of the opioid system in the agmatine antidepressant-like effect in the forced swimming test. Neurosci Lett 381: 279-283. 